\title{
Research on the Reform Orientation of Circuit Course Guided by Improvement of Professional Quality of Electrical Engineer
}

\author{
Qing Xie \\ School of Electrical and Electronic Engineering \\ North China Electric Power University \\ Baoding, China \\ Mengyuan He \\ State Grid Hebei Procurement Branch \\ State Grid \\ Shijiazhuang, China \\ priangelina@163.com
}

\author{
Yumin Ge \\ School of Electrical and Electronic Engineering \\ North China Electric Power University \\ Baoding, China \\ Guishu Liang \\ School of Electrical and Electronic Engineering \\ North China Electric Power University \\ Baoding, China
}

\author{
Xiao Yan* \\ School of Electrical and Electronic Engineering \\ North China Electric Power University \\ Baoding, China \\ yanxiao_2013@126.com
}

\begin{abstract}
The development of the society requires the promotion of the professional qualities of electrical engineers. It is manifested in the need for solid professional knowledge, strong engineering quality, practical ability, and innovative consciousness. Circuit course is a professional basic course that plays a decisive role in the cultivation of electrical engineers. It has characteristics of theoretical abstraction, strong practicableness and a great deal of concept, principle, and formula. The phenomenon of students' superficial and theoretical learning in circuit is widespread. This paper explores the reform direction of Circuit course teaching in the perspective and height of improving the professional quality of electrical engineers. This helps to cultivate electric engineers that are more suitable for the development of modern society.
\end{abstract}

Keywords-electrical engineer; professional quality; circuit; course reform

\section{ELECTRICAL ENGINEER PROFESSIONALISM}

Electrical engineer refers to technical personnel who obtains "Registered electrical engineer certificate of the People's Republic of China" and engages in electrical engineering design and related business ${ }^{[1,2]}$. It generally can be divided into electrical intelligent engineer, building weak electrical engineer, registered electrical engineer and inverter

This paper is subsidized by research and practice of higher education teaching reform project in Hebei province (research and practice of hybrid teaching in circuit course centered on the improvement of students' ability, 2017GJJG211), and North China Electric Power University (Baoding)

common platform course quality improvement project. technical engineer. Among them, the registered electrical engineers are highly valued by the power system practitioners due to their high comprehensive quality and heavy responsibilities.

The professional quality of electrical engineers is manifested in solid professional knowledge, strong engineering quality, practical ability, innovation consciousness, and good communication skills which need strong professional and social responsibility. The intelligent design of buildings in recent years is taken as an example to illustrate the professional accomplishment of electrical engineers in practical engineering. There are no comprehensive national code and standard in the field of intelligent building design which makes the work for electrical engineers more difficult. Electrical engineers are required to keep up with the intelligent development of buildings in time to understand the latest development of the field. They should constantly update the knowledge reserve to enrich the mind, master various building intelligence system and technical performance of the new product. At the same time, the electrical engineer must have comprehensive business level and working ability, such as project budget, bidding, coordination of various relations, etc. Only by possessing the above basic qualities can electrical engineers do well in all aspects of electrical engineering deeply, specifically and accurately.

As the saying goes, things remain essentially the same despite all the apparent changes. Such tremendous knowledge reserve and capability system ultimately need a very solid comprehensive professional knowledge to rely on. Professional 
knowledge is the cornerstone of the professional quality framework of the entire electrical engineer. Obviously, its role cannot be underestimated.

Electrical circuit is an important professional course in the specialized courses ${ }^{[3-7]}$. Its content is the preliminary basis of the course of electrical machinery, electric power system analysis, power electronic technology, electromagnetism, power system relay protection. Also it contains a large proportion of overlapping content like basic concepts, basic principles and basic analysis methods which run through the teaching of the whole course. The basic knowledge of the circuit and the cross-examination of other disciplines account for nearly $60 \%$ of the registered electrical engineers' basic examination. However, students may easily produce the emotion of weariness to learn in the learning process because of the characteristic of abstract theory and principle, numerous formulas in circuit course.

\section{Current Teaching Characteristics of Circuit COURSES}

Circuit course is a professional basic course to learn the circuit theory. It discusses the elementary concept, basic principle, and analysis foundation and calculation method of the circuit based on the circuit analysis which makes it an important technical foundation course in electrical engineering major. It also has a rigorous theoretical principle and strong logicality that is crucial to improve students' logical thinking ability and establish the combination of theory and practice in analyzing and solving problems in undergraduate stage.

Circuit has a wide range of contents, concepts, theorems and mathematical derivations. In teaching process, there are phenomenon of bias theory, weight base, less practice and less application. Previous circuit teaching focuses on basic concepts, basic models and basic analytical methods. It mostly discusses the classic circuit which is made up of the ideal model. The components involved in the theoretical teaching are basically ideal components. So it makes it difficult for students to abstract the corresponding circuit models from real life components which lead to the lack of the concept of mathematical modeling in circuit elements and the inability to establish the real circuit based on the ideal model. In this way, the knowledge that students have mastered will be an armchair strategist, so they can only solve the problem by routine. This means that they have no idea how to solve it when confronted with practical problems or new types of problems. In the face of the real phenomena in life, the interpretation of the phenomenon will be more clueless. Worth mentioning, after the completion of circuit course, quite a few students cannot use a part of common components, instruments and meters, and even don't know how to analyze the experimental data, which is completely out of touch with actual requirements.

According to the characteristics and existing problems of the above disciplines, it is urgent to adjust the teaching content in order to improve the teaching quality of education. The circuit curriculum should be reformed and the education teaching mode should be improved. Only in this way can students really apply and practice what they have learnt. The extension of circuit theory in the following specialized courses enables students to feel the universality of the knowledge, methods and principles in the circuit class. And the connecting function of circuit curriculum will be performed. In addition, they can realize the combination of theory and practice. Our school's "excellent engineer program" will be better improved by the reform of circuit theory course.

\section{Circuit Curriculum Reform IN the Direction of ELECTRIC ENGINEER'S VOCATIONAL QUALITY IMPROVEMENT}

\section{A. The Combination of Content Guided Teaching and Other Teaching Methods}

In the learning process of the circuit, the attitude of most students is active and serious, and many students have independently made pre-class preview and after-school review. However, students often have no specific focus in the process of pre-class preview, which means they usually read blindly. This requires teachers to adopt content guided teaching. Before each class, teachers should give the main points, priorities and difficulties of the next lecture. It should specific to the key formulas and exercises, instead of limiting to the rules and regulations. In this way, students' interest will be inspired, good learning habits and enthusiasm can be cultivated, and they can be guided to study on their own. It improves students' learning efficiency and classroom teaching effect, and learning process is more targeted.

On the teaching means, the traditional teaching methods should be combined with modern teaching technologies and means such as multimedia, simulation software according to different teaching content. Teaching contents can be enriched and atmosphere of the classroom can be come alive by this means.

(1) By adopting the combination of multimedia courseware and blackboard writing teaching methods, not only the core content in blackboard writing can be highlighted and deepened, but also can effectively make up for the disadvantage of information poverty, old content in traditional teaching mode. By this way, the teaching content will be more clear and comprehensive, and the teaching process will be more vivid. It is an ideal way of teaching. At the same time, more attention should be paid on the continuity of the picture in the multimedia courseware, so that the switch of the page can be well connected to facilitate students' understanding and memory.

(2) Flash animations can be interspersed in the classroom to show some abstract, difficult principles and concepts to make students learn concisely and intuitively. For example, concepts such as the reference direction branch current and loop current, sinusoidal and rotating phasor can be made into a flash animation. These abstract concepts can be intuitively and vividly displayed, so it becomes more understandable for students.

(3) Virtual experiment platform EWB and Matlab software can be used to simulate the circuit. The experimental principles, methods, process, results can be demonstrated visually. Compared with theoretical analysis, students can understand the related circuit phenomenon more deeply and comprehensively. To some extent, the organic combination of 
the theoretical knowledge and practical application can be realized.

\section{B. Cohesion Teaching Content and Engineering Application}

As a professional basic platform course, the circuit course should not only enable students to master basic theories and analytical methods, but also cultivate and improve their engineering consciousness. It requires a conscious emphasis on the practical application of theories and methods in the teaching process. Therefore, teachers should undertake a certain amount of research work in the classroom teaching. In the daily work of teaching and research practice, teachers should not only improve their academic level, ability of technology research and development, but also connect the scientific research achievements and experience seamless with teaching needs and content. From the result of scientific research, the content related to the classroom teaching should be summarized as the teaching case. The professional teaching level should be improved. For example, in the teaching of relevant content of circuit model, the actual engineering background of the abstract model, the concrete abstract process and the difference between the models should be introduced. The corresponding relationship between the idealized circuit element model and the actual circuit device can be initially realized. In the course of introducing dynamic circuit, except for introducing various dynamic circuit analysis methods, the application of dynamic circuit in practical circuit should also be introduced.

This combination of engineering background and engineering teaching method stimulates students' interest and desire. Their innovative consciousness and ability in practical application can be improved in real sense. Students can learn and understand the theory and essence of circuit theory more profound. The most important thing is the cultivation of students' engineering quality can be consolidated. It plays a important role in the cultivation and improvement of the students' professional quality. It fully meets the requirements of the reform of the circuit theory course system developed by our school's "excellent engineer program".

\section{Combined Teaching Content with College Students' Innovative Practice Activities}

Improving students' ability to innovate is a key part of talent cultivation. Electrical engineers must also have this ability. Our university advocates innovative experimental reform mainly with undergraduate students. The aim is to arouse students' initiative, enthusiasm and creativity, stimulates students' innovative thinking and consciousness, so that students can gradually grasp the methods of thinking and solving problems, and improves their ability of innovative practice.

In the process of circuit teaching, teachers can provide useful guidance to students' innovative practice activities when they teach relevant knowledge points, which can improve students' ability to combine theory with practice.

\section{Combined classroom experiment and open- experiment after class}

Experiment is a necessary and important part which often be ignored in circuit teaching activity. In order to deepen the students' understanding of knowledge in practice, cultivate qualified electrical engineering professionals who can use brains as well as hands for the society, the circuit experiment should be reformed.

In the teaching process of the daily course, the interpretation of features and functions of some basic components in the circuit (e.g., resistor, capacitor, inductor, transformer, etc.) should be combined with physical objects and demonstration experiment of related circuits to lead to its corresponding circuital law. Thus, students can have a deep understanding of experimental devices, experimental methods, experimental procedures and follow-up notes while accepting new knowledge.

Our school proposes a reform of "autonomous choice" electrician experiment teaching which is suitable for students' specialty and a reform of "autonomous design" electrician experiment teaching which is highlight for engineering application. Circuit experiment reform is focus on students' own initiative and independence, rather than the connection, adjustment and record of the test data mechanically in simple circuit according to the previous circuit experiment. Students should be encouraged to design the experimental scheme and the specific wiring. And they should be motivated to formulate the final plan independently. They should complete the experiment independently in the laboratory after supervising the teacher. Through the form of the knowledge system according to the independent experiment design integrates theoretical knowledge; students can apply their knowledge indeed. At the same time, the ability of active learning and innovation will be cultivated, and the practical ability of working will be improved.

At the same time, the circuit experiment is not limited to the class time. The laboratory is transformed into an open place. As long as the students have needs, meanwhile the laboratory has free laboratory equipment, students' need for independent experiments can be satisfied. This greatly increases the student's experiment time, dramatically enriches the student's after-school life, enhances the student's hands-on ability, and plays an important role in the cultivation of qualified electrical engineers.

\section{CONCLUSION}

In today's society, all kinds of new knowledge and new ideas are emerging constantly. The field of electrical expertise is becoming broader and broader. The pace of electrical technological change is getting faster and faster. Thus, higher requirement for electrical engineers, especially for electrical engineers is needed. As an institution of higher learning in the field of electricity, our university takes the circuit course reform direction inquiry as the breakthrough point to strengthen the education teaching of students' professional knowledge. The improvement of education and teaching quality is a systematic project, which is very broad and academic, and it needs a long time to explore, summarize and 
improve. Based on the analysis of the current situation and characteristics of the current course teaching, we have put forward and practiced several reform measures by exploring the direction of circuit curriculum reform. It shows an effective result. Reform and explore will be continued in practice, improving and perfecting the circuit teaching system and method with characteristic of NCEPU. Efforts will be made to cultivate high-quality graduates in electric field, convey electrical engineering professionals with high professional quality for the society.

\section{REFERENCES}

[1] Liming Wei, Chenghao Han, Zongze Wang. "Study on electrical engineering and automation major teaching reform under the electrical engineer system,” China construction education. vol. 4, pp. 47-49, 2010. (In Chinese)
[2] Shuang'an Weng. "The Registered Electrical Engineer System and Teaching Reform of Electrical Engineering,” China Modern Educational Equipment. vol. 12, pp. 92-94, 2007. (In Chinese)

[3] Shuangxi Cui. ““Circuit” curriculum reform and exploration,” China Electric Power Education, vol. 29, pp. 40-41, 2013. (In Chinese)

[4] Xiaosan Ma, Jiayan Zhang, Zhaoming Li, Yan Wang. "Research on the Curriculum Teaching Reform of Electric Circuit Course,” Journal of Anhui University of Technology (Social Sciences Edition). vol. 2, pp. 113-114, 2011. (In Chinese)

[5] Stefan Borik, Ivo Cap. "Arterial segment model evaluation by the means of two port electrical circuit theory - Properties of different arterial segments at various hematocrit values,” IEEE. Elektro. pp. 482-488, July. 2016.

[6] Xiyou Chen, Guanlin Li, Huiwei Zhou. "Several Teaching Practices about Circuit Theory Course," Journal of Electrical \& Electronic Education. vol. 2, pp. 1-4, July. 2014. (In Chinese)

[7] Shishi Liu, Keping Liu, Chunhua Pu. "Discussion on Teaching Method of The Circuit Curriculum,” Heilongjiang Education. vol. 12, pp. 88-90, 2010. (In Chinese) 